\title{
The Application of Interactive Teaching Mode in Network Learning Space_-Taking College English Online Learning During the COVID-19 Epidemic Period as an Example
}

\author{
$\mathrm{Li} \mathrm{Cao}^{1}$ and Fen Zhang ${ }^{1, *}$ \\ ${ }^{1}$ English Department, Chengdu Medical College, Chengdu, Sichuan 610038, China \\ *Corresponding author. Email: zhangfen@cmc.edu.cn
}

\begin{abstract}
The interactive teaching mode has been widely used with which teachers and students can make great achievements. However, with the outburst of the COVID-19 pandemic, it is of great necessity to carry out teaching in network learning space. In order to overcome the shortcomings of on-line teaching, the interactive teaching mode was applied in network learning space in this case design. By carrying out pre-class interaction, in-class interaction and after-class interaction, students' motivation for learning English was enhanced and the on-line teaching effects were greatly improved. This study can shed some light on the reform of network teaching and the exploration of mixed teaching after the COVID-19 pandemic.
\end{abstract}

Keywords: Interactive teaching; Network learning space; Case design; COVID-19 pandemic

\section{INTRODUCTION}

At present, interactive teaching mode has been recognized by most teachers and widely used in teaching classes, especially in language teaching classes. Many scholars have proved that interactive teaching mode can effectively improve the teaching effect through practice. But most of these studies have focused on classroom teaching in the classroom, with little reference to online teaching. Since the outbreak of COVID-19, teachers in schools across the country have been learning to use a variety of online resources to teach online. However, compared with traditional classroom teaching, online teaching has certain disadvantages, especially in the aspect of interaction. In order to overcome the disadvantages, stimulate the students' learning motivation and interest, and enhance the students' learning ability, it has become a trend to apply the interactive teaching mode in the network learning space.

\section{INTERACTIVE TEACHING THEORY}

With the development of constructivism, Palincsar (1984:117-175) proposed interactive pedagogy[1].He believes that the teaching process is a two-way and multi-direction flow of teaching content between teachers and students and between students. In this process, teachers cannot output all the time, nor can they give all the time to students. Teachers should realize teacher-student interaction and student-student interaction according to the teaching content. Rivers(1987) believed that interaction was the key to communication in language teaching[2]. Along with class interaction, students are given the opportunity to behave and talk. In the interactive activities, students' language skills are also trained and developed. Brown in "according to the principle of teaching: the interactive language teaching" (2001:159) pointed out that in communicative language teaching, the interaction is the core of communication, the communication itself is the best way to learn communication[3]. Brown (2001:159-161) put forward several important principles of interactive teaching, namely the automaticity, intrinsic motivation, policy input, in the face of risk, the language and culture, interactive language and communication skills.

\section{THE CHARACTERISTICS OF NETWORK LEARNING SPACE}

Zhu Zhiting et al. (2015:1-9) defined online learning space as a virtual space based on real name system, which is oriented to formal and informal learning, can support the teaching and learning process and the communication between different role subjects (teachers, students, parents, etc.), and runs on a certain learning support service platform[4].To sum up, it has the following characteristics: (1) Network learning space breaks through the limitations of time and space. Students do not have to be confined to the classroom and class time; they can make full use of their spare time to conduct independent learning through the Internet. This greatly expands the learning space and improves the utilization of time. (2) The network learning space provides students with rich learning resources. These 
learning resources range from the training of basic language skills such as listening, speaking, reading, writing and translation to the appreciation of literary and cultural works. Students can broaden their horizon and improve their level from it. (3) Network learning space gives students great freedom. Students can choose materials according to their own level and interest, stimulate their interest in learning English, establish self-confidence, and constantly enhance their motivation to learn English.

Network learning space in the traditional classroom teaching and extracurricular learning bring positive influence at the same time, there are some negative effects: (1) Compared with the traditional face-to-face teaching, online learning space, teachers and students who are separated by the computer screen, lack of motivation and interest in each other's communication, so it is difficult for students to learn from teachers' personality and peer model. (2) The network learning space lacks the collective atmosphere of learning in the classroom. Furthermore, the lack of teacher management and peer supervision makes it easy for students to distract themselves. Therefore, it is particularly important to apply the interactive teaching mode to the network learning space. This helps to make full use of the advantages of the network, overcome its disadvantages and improve students' language learning ability. The following is an example of college English network learning during the epidemic.

\section{THE APPLICATION OF INTERACTIVE TEACHING MODE}

\subsection{Pre-class Interaction}

In traditional classroom teaching, teachers release preview content and homework before class, which lacks timely feedback and communication. In the network learning space, the application of interactive teaching mode is the interaction before class. The pre-class interaction includes three links: the teacher makes preview videos, the students watch the video and ask questions, and the teacher gives feedback.

When making preview videos, teachers should pay attention to several aspects. First, the time of the video should not be too long, generally within 20 minutes. A video of long time is easy to make students feel tired. Second, the difficulty of the video material should be moderate, because too difficult material make students lose confidence while too simple material make students lose interest. Third, the video material should be interesting and varied so as to stimulate their motivation. For example, when making the preview video of Text A Fame, Unit 3 of the new century College English Comprehensive Course 4, the author introduced a brief comment on a famous singer, so that students could have a certain understanding of the positive and negative effects of fame. Then the teacher explained the important and difficult words to help the students clear off the language barriers. The following is the introduction of the article paragraph and the main idea, so the students have a certain understanding of the main content of the text.

Students watch recorded preview videos through the online learning platform Super Star Learning. This kind of autonomous learning is not restricted by specific space and time, but teachers can set a deadline and ask students to record what they do not understand and consult with teachers through social media software such as QQ.

After the teacher collects the problems that students encounter in the preview process, he can classify the problems, including the common problems and the individual problems. The teacher left the common questions to the network class for organizing discussions, and gave feedback to the individual questions, which fully realized the interaction before class.

\subsection{In- Class Interaction}

In the traditional classroom, the interaction between teachers and students and between students is face-to-face communication with rich facial expressions and body postures, which has great appeal and can mobilize the enthusiasm of students to the greatest extent. In order to overcome the disadvantages of lack of face-to-face communication in the online learning space, it is necessary to make full use of the social media software such as the live broadcast room and QQ live broadcast. It includes two aspects: teacher-student interaction and student-student interaction.

During the live broadcast, the teacher can first answer the common questions that students encounter in the preview process, and then explain the long and difficult sentences in the text. When explaining the long and difficult sentences in the text, the teacher can ask the students to talk about their own understanding first. Students can express their opinions by "grabbing the mike" or "assigning". For example, the sentence "Failure often serves as its own reward for many people" in the third paragraph of Text A Fame, Unit 3 of the New century University English Course 4. Different people have different understandings of this sentence, and it is difficult to understand its true meaning literally. Students are asked to think and answer first, and then the teacher gives comments and answers. In this way, the interaction between teachers and students in cyberspace learning can be realized.

In classroom teaching, the interaction between students and students is mainly realized through group discussion. In the network learning space, teachers can organize students to discuss the topic of the text in depth. The way of discussion is that students upload their views to the QQ group by text or voice, and everyone can share their views in time, and then the teacher gives comments and summaries. This is when live streaming and chat groups can be combined. For example, after studying Text A Fame in Unit 3 of New Century College English Comprehensive Course 4, the author organized students to discuss "The Advantages and Disadvantages of Being 
Famous". The students actively participated in the discussion and benefited from it. In this way, students can interact with each other in cyberspace.

\subsection{After-class Interaction}

At the end of classroom teaching, teachers usually interact with students by assigning homework and correcting homework. After the end of the class based on the network learning space, the ways of interaction are more diversified, mainly including the arrangement and feedback of online homework and the evaluation of online learning.

Teachers release homework through the online platform of Super Star Learning Tong and set the deadline for submission. After students submit homework, teachers will correct it. Due to the timeliness of the network, students can get feedback soon after the teacher corrects, so that they can reflect on and improve the problems existing in the learning process. Teachers can post assignments on online platforms, including vocabulary, listening, reading, writing and translation. Among them, oral training can also be interactive through the network platform. The teacher will release a speech topic related to the single topic. The students will prepare the speech draft and record the speech process. Then upload it to the teacher. According to the recording, the teacher grades and puts forward suggestions for improvement. This method can arouse students' oral enthusiasm and build up their confidence in oral English.

The evaluation of online learning includes teacher self-evaluation, student self-evaluation and mutual evaluation between teacher and student. After learning a unit, the teacher should self-reflect on the teaching design of the three links before class, during class and after class, and consider whether the teaching objectives are achieved and constantly adjust the teaching measures. After completing the study of a unit, students are also required to make a self-evaluation of the knowledge they have mastered in the unit. If there is anything they do not understand, they can timely feedback to the teacher through the network. In the teacher-student mutual evaluation, the teacher finds out the shortcomings of the students, and the students also give feedback to the teacher's teaching, including three links of mutual evaluation before class, class and after class. This kind of evaluation method is communicated through network media, which fully realizes the interaction between teachers and students.

\section{CONCLUSION}

Today, with the rapid development of network technology, online classroom makes teaching no longer limited by space and time and provides convenience for personalized learning. However, before the outbreak of the epidemic, most teachers only used the network platform to increase learning resources and communication opportunities, few teachers use the network platform to carry out live classes, but after the outbreak of the epidemic, teachers are required to carry out live classes with the help of the network space. Online courses have attracted more attention to the individualization and interactivity of learning, and students' online learning behavior tends to be personalized. Hierarchy has become a common feature of online classes.[5] In the network learning space, the role of teachers and students in the classroom has changed, and the principal position of students has been highlighted. Teachers should change from "classroom speaker" to "learning guide", stimulate students' interest in learning, tap students' independent learning potential and the interaction between learning subjects.[6]In order to overcome the disadvantages of online teaching, the author apply interactive teaching model to college English network teaching space. Through pre-class interaction, in-class interaction and after-class interaction three links, the students' learning interest are promoted, the communication between students and students are increased and students' language learning ability are improved. However, this teaching mode still needs to be improved. It is expected to provide a reference for teachers who are teaching in cyberspace, as well as for the reform of online teaching and the exploration of blended teaching after the epidemic.

\section{REFERENCES}

[1] Palincsar, A.S.\& A.L Brown.1984. The reciprocal teaching of comprehension-fostering and comprehension-monitoring activities $[\mathrm{J}]$. Cognition and Instruction(7):117-175.

[2] Rivers, Wilga M.(Ed). 1987. Interactive Language Teaching [M].London: Cambridge University Press.

[3] Brown.H. Doughlas. Teaching by Principles. An Interactive Approach to Language Pedagogy [M]. Beijing: Foreign Language Teaching and Research Press, 2001.

[4] Zhu Zhiting, Yu Xiaohua, et al. Students' Personal Learning Space and Its Information Model Oriented to "All Tons"[J].China Electronic Education, 2015 (8) : $1-9$.

[5] Mou Wei. Online Education of Preventive Medicine through Interactive Learning Mode Combined with Diversified Online Classes During the Epidemic Period [J]. Gansu Science and Technology, 2020,36(19):75-77.

[6] Wang Hongyun, Zhai Xing. Research on the Construction of Multi-dimensional Hybrid Teaching Mode Based on Network Learning Space: Take Network Learning During the Pandemic as An example [J]. China Medical Education Technology, 2020,34(6):773-777. 